\title{
GUEST EDITORIAL LIFE ON A TROLLEY
}

Grainne McPolin Editor of the Irish fournal of Anaesthetic and Recovery Nursing
Trolleys! What is it about them that provoke reactions ranging from fear, anxiety to trepidation? Or is it about feeding the imagination of the masses by using the image of a trolley in news items to determine the less than attractive state of the health services?

What is it about this image that inspires so much debate in the media when the public are drip fed (to excuse the metaphor) negative impact pictorial headings such as: 'lying on a trolley' or 'waiting on a trolley for up to 20 hours?' As headlines go, we fail to realise that perhaps the trolley is probably one of the most important items of hospital furniture that features so prominently in our daily routine as Anaesthetic and Recovery Nurses. The image is perhaps a recurring motif of hospital life, a form of transport, conveyance, communication, comfort or even discomfort (as seen in A\&E departments). It is also a useful tool of observation and maintenance of important physiological processes that need to be monitored closely during the induction and emergence from the state of anaesthesia.

There appears to be a difference in the perceptions of those observers of the news coverage albeit negative and those who work with them and finally those individuals who have been conveyed on them as patients. There is a belief that the person becomes a patient not when they are admitted to hospital but essentially when they experience what is like to be on a trolley. They lose their identity; they are removed from their personal world of family and friends and are transported into a strange environment through the hospital, from the ward to the theatre ....horizontal!
How can we comprehend the flow of emotions going through the patients' mind during their journey through this forbidding and impersonal hospital environment? Have we as nurses had any experience as patients on trolleys? How have we dealt with it? Forgotten it quickly? Taken it for granted because we work with them on a daily basis? Did we feel in control or were we just 'switched off'? Wiped it clean out of our collective memory?

One thing that stands out in my own memory was one of being a patient on a trolley experiencing an interminable wait at the theatre holding bay and feeling very exposed to the many passers by, it felt like being in the local high Street on a Saturday afternoon.

Admiration can be attributed to some of the clever cinematographers of our time who can use their art in an effort to bridge this awning gap between the news reader and life on a hospital trolley by balancing themselves and their camera on the end of a trolley and recreating a moving image of fluorescent lights, white walls, and people passing by in both directions. The real experience can be acquired by the use of role play in the hospital setting. At quiet moments in our department, we play out the experience of being conveyed in a trolley, up and down the lifts, along the corridors, checking each other in to theatres, by this re-enactment we can learn to create the transition from person to patient to individual

Grainne McPolin 


\section{EDITORIAL}

I was not going to write an editorial this month, but several things have prompted me to do so. The first is that by the time this edition of the journal is published I will have taken up a new position as a lead practitioner in a new 15bedded PACU. Having been in education for some twelve years I have decided to go back to clinical practice. I have felt for some time that I am not making a difference in the job that I do, and the only way that I can is to go back to clinical practice. However the thing that has always stopped me has been the salary differential, like everyone else I have a mortgage to pay and all the other expenses of daily living. I could have gone back and been in a role that would have given me the salary but not the patient contact that I crave so it has never really been an option.

However in Epsom, Surrey a new unit is being built. It is part of the Government plans to reduce waiting lists and is one of the Direct Treatment Centers. It will only be undertaking hip and knee replacements and the idea is that the patients will be discharged within six days. How will this be achieved I hear you ask? The plan is that the patients will be involved right from preoperative assessment in their care pathway and from the moment of preoperative assessment discharge will be discussed and mechanisms put in place to facilitate this. If I am honest this is not what really attracted me it was two other things. First was that the salary is mapped to agenda for change and thus I can have a clinical role for a salary that will sustain everyday living. Secondly the unit will be nurse led and so it will be nurses who will facilitate the patient pathway through the unit. I feel that these issues will mean that I can have a fulfilling job without dropping my salary.

Confidentially, because I know you will not tell anyone, I am slightly nervous, twelve years is a long time to be in a job and I will be leaving some very good friends and colleagues behind. But as I say frequently to anyone who will listen 'life is not a rehearsal' we only have one and so we must take all the opportunities that are offered, and if they are not, go out and find them and enjoy life.
The second reason for writing this editorial is that I read Maria Rollin's President's letter and I thought she made some salient points. I think the message she is giving is that we as anaesthetic and recovery nurses have a strong sense of out self worth, which of course you all know, but I also think she is telling us that if there is not, there should be mutual respect between professionals, and certainly I am looking forward to working with Maria, and the advent of a new form of anaesthetic practitioner.

The final reason is the guest editorial from Grainne McPolin the editor of the Irish Journal of Anaesthetic and Recovery Nursing. I think she has given an interesting perspective on trolleys. However it was the last part that I found fascinating, when she said that the staff where she worked role played what it was like to be a patient by putting themselves on trolleys, being wheeled through corridors and then being checked into theatres. I think this is a brilliant idea, there is nothing like experiencing what the patient experiences to become more empathetic. I say this through personal experience of being a patient. I think when this happened to me my practice developed in ways I did not think was possible. So go on everyone out there give it a go, do a bit of role play when it is quiet and see what it feels like to be a patient.

I know it is early, but have a great Christmas and a happy new year

Best wishes

Melanie Oakley 